\title{
The potential of Ganoderma lucidum extracts as bioactive ingredients in topical formulations, beyond its nutritional benefits
}

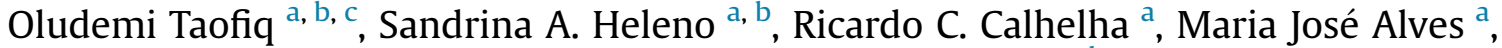 \\ Lillian Barros ${ }^{a}$, Ana M. González-Paramás ${ }^{c}$, Maria F. Barreiro ${ }^{\text {b }}$, Isabel C.F.R. Ferreira ${ }^{a}$, * \\ ${ }^{a}$ Centro de Investigação de Montanha (CIMO), Instituto Politécnico de Bragança, Campus de Santa Apolónia, 5300-253 Bragança, Portugal \\ ${ }^{\mathrm{b}}$ Laboratory of Separation and Reaction Engineering (LSRE), Associate Laboratory LSRE/LCM, Polytechnic Institute of Bragança, Campus de Santa Apolónia, \\ 1134, 5301-857 Bragança, Portugal \\ ${ }^{c}$ GIP- USAL, Unidad de Nutrición y Bromatología, Faculty of Pharmacy, University of Salamanca, Campus Miguel de Unamuno, 37007 Salamanca, Spain
}

\section{A R T I C L E I N F O}

\section{Article history:}

Received 30 June 2017

Received in revised form

22 July 2017

Accepted 25 July 2017

Available online 29 July 2017

\section{Keywords:}

Ganoderma lucidum

Nutritional composition

Phenolic and triterpenic acids

Bioactive ingredients

Cosmeceuticals

\begin{abstract}
A B S T R A C T
Ganoderma lucidum was characterized in terms of nutritional value and chemical composition. Thereafter, ethanolic Soxhlet extracts were evaluated for antioxidant, anti-inflammatory, antityrosinase, antimicrobial and cytotoxic effects, and further characterized in terms of phenolic acids, polysaccharides and triterpenoids. Finally, the obtained extracts were tested as cosmeceutical ingredients. G. lucidum proved to be a source of macronutrients and important bioactive compounds such as terpenoids, specially triterpenoids, and polysaccharides. In the extracts, ganoderic acids $\mathrm{C} 2, \mathrm{~A}$ and $\mathrm{H}$ were the most abundant triterpenic acids and protocatechuic, $p$-hydroxibenzoic and syringic acids the identified phenolics. The developed cosmeceutical formulation preserved the extract bioactivities, presented a lightyellow colour and a $\mathrm{pH}$ of 4.6, which is considered appropriate for cosmeceutical's design. Behind the important nutritional/bioactive composition of $G$. lucidum, a potential towards its valorisation in the field of cosmeceuticals is foreseeable, as deduced from the bioactivities of its ethanolic extract and preservation in the tested formulation.
\end{abstract}

() 2017 Elsevier Ltd. All rights reserved.

\section{Introduction}

Ganoderma lucidum (Curtis) P. Karst. is a medicinal mushroom with interesting chemical composition imparting nutraceutical properties and pharmacological benefits either as immune suppressors, hypocholesterolemic agents or as coadjutant treatments in diseases such as cancer, hypertension, insomnia, anorexia, dizziness and chronic hepatitis, among others (Zhao et al., 2016). Currently, G. lucidum is one of the most sought after medicinal mushrooms in oriental countries, being popularly known as Lingzhi in China, Reishi in Japan and Yeongji in South Korea (Baby et al., 2015; Bishop et al., 2015; Grienke et al., 2015). This species is rich in several bioactive compounds mainly polysaccharides, terpenoids, nucleotides, steroids, fatty acids, proteins, and glycopeptides, being the polysaccharidic and triterpenic components the most reported ones (Liu et al., 2016b).

The polysaccharide composition of G. lucidum (GLP) includes

\footnotetext{
* Corresponding author.

E-mail address: iferreira@ipb.pt (I.C.F.R. Ferreira).
}

several monomers (glucose, mannose, galactose, fucose, xylose, rhamnose and arabinose) that are described to contribute significantly to its immunomodulatory, antioxidant, antitumour and antibacterial properties (Ferreira et al., 2015; Liu et al., 2016a). Among the terpenes, the triterpenes (ganoderic acids, ganoderenic acids, ganoderols and lucideric acids) are the most abundant ones, having been reported to be responsible for its antitumour, antiinflammatory, antioxidant, anti-hepatitis, antimalarial, hypoglycemic, antimicrobial and anti-HIV-1 properties (Baby et al., 2015; Bishop et al., 2015; Grienke et al., 2015; Van Nguyen et al., 2015). The phenolic composition of G. lucidum has also been widely studied and phenolic acids represent the most prominent class including chlorogenic, cinnamic, gallic, protocatechuic, $p$-hydroxybenzoic and $p$-coumaric acids. These molecules have been identified as contributors to its antioxidant, antimicrobial, antityrosinase and anti-inflammatory properties (Heleno et al., 2013, 2012; Min-Young et al., 2008; Sheikh et al., 2014; Stojković et al., 2014). Besides all these bioactive compounds, G. lucidum nutritional composition reveals high potential to be used in the design of dietary supplements (e.g., tablets and capsules) for oral 
administration (Stojković et al., 2014).

The use of $G$. lucidum bioactive extracts in the design of cosmeceutical formulations for topical application is receiving special attention. It is supported by existing reports on their power as tyrosinase inhibitors, inflammatory mediator suppressors and as photoprotective agents, which makes them multifunctional ingredients that can be used to control hyperpigmentation, suppressing skin inflammatory diseases and preventing skin photoaging (Taofiq et al., 2016a, 2016c; Wu et al., 2016). Because of the above mentioned interesting properties, several mushroom extracts and their bioactive components are either presently used or patented to be used as cosmetics ingredients (Wu et al., 2016). There are also studies on the stability and rheological properties of several vehicles added with these bioactive ingredients for application in cosmetic, nutraceutical and pharmaceutical industries (Li et al., 2013b; Liu et al., 2016).

Herein, the fruiting bodies of G. lucidum were studied: i) in terms of nutritional and chemical composition to highlight its potential to be consumed as functional foods; ii) as a source of bioactive compounds, namely, triterpenic and phenolic acids which show antioxidant, anti-inflammatory, antityrosinase, antitumour and antimicrobial activities, for cosmeceutical purposes. This last concept was studied by incorporating $G$. lucidum ethanolic extracts in a cosmetic base cream, which was further characterized in terms of physico-chemical and bioactive parameters.

\section{Materials and methods}

\subsection{Standards and reagents}

Acetonitrile (99.9\%), $n$-hexane (95\%) and ethyl acetate (99.8\%) were of HPLC grade from Fisher Scientific (Lisbon, Portugal). Fatty acids methyl ester (FAME) reference standard mixture 37 (standard 47885-U) were purchased from Sigma (St. Louis, MO, USA), as well as phenol, starch, ursolic acid, ganoderic acid A, alpha and delta tocopherols, sugar standards and $p$-iodonitrotetrazolium chloride (INT). Phenolic standards were obtained from Extrasynthèse (Genay, France). Tocol and beta and gamma tocopherols (50 mg/ $\mathrm{mL}$ ) were purchased from Matreya (Pleasant Gap, PA, USA). 2,2Diphenyl-1-picrylhydrazyl (DPPH) was obtained from Alfa Aesar (Ward Hill, MA, USA). Dulbecco's modified Eagle's minimum essential medium (DMEM), fetal bovine serum (FBS), penicillin, streptomycin, Griess reagent system (Promega), DMSO, sulphorodamine B (SRB), lipopolysaccharide (LPS), 3,4-dihydroxy-Lphenylalanine (L-DOPA), and mushroom tyrosinase enzyme were obtained from Sigma-Aldrich Co. (Saint Louis, MO, USA). The culture media Muller Hinton broth (MHB) and Tryptic Soy Broth (TSB) were obtained from Biomerieux (Marcy l'Etoile, France), as also, blood agar with $7 \%$ sheep blood and Mac Conkey agar plates. Perchloric acid 70\%, glacial acetic acid and sulphuric acid were purchased from Fischer chemicals (Loughborough, UK). Vanillin was purchased from Labkem (Barcelona, Spain), ursolic acid was purchased from Acros Organics (New Jersey, USA) while all other chemicals and solvents were of analytical grade and purchased from common suppliers. Water was treated in a Milli-Q water purification system (TGI Pure Water Systems, Greenville, SC, USA).

\subsection{Ganoderma lucidum samples}

The fruiting bodies of Ganoderma lucidum were provided by Bioreishi - Agricultura Biológica, Lda, Portugal (Reishi producers; Batalha, Portugal) as dry material. The specimens were reduced to powder (20 mesh) and mixed to obtain homogeneous samples. For all the experiments three independent samples were analysed and all the assays were carried out in triplicate. The results are expressed as mean values \pm standard deviation (SD).

\subsection{Nutritional properties and chemical composition of G. lucidum fruiting bodies}

Proximate composition. The proteins, fat, carbohydrates and ash were determined using standard AOAC procedures (AOAC International, 2016). The sample crude protein content $(\mathrm{N} \times 4.38)$ was estimated by the Kjeldahl method; the crude fat was determined using a Soxhlet apparatus by extracting a known weight of sample with petroleum ether; the ash content was determined by incineration at $600 \pm 15^{\circ} \mathrm{C}$. The total carbohydrate was calculated by difference and the energy content estimated using the following equation: Energy $(\mathrm{kcal})=4(\mathrm{~g}$ protein $)+4(\mathrm{~g}$ carbohydrate $)+9(\mathrm{~g}$ fat).

Sodium chloride content. The salt concentration in G. lucidum was determined according to Mohr's Method, similarly to the procedure described by Osaili et al. (2014), with slight modifications. Briefly, the sample $(1 \mathrm{~g})$ was suspended in distilled water $(20 \mathrm{~mL})$ and filtered. The procedure was repeated at least 5-fold and the $\mathrm{pH}$ adjusted to $\approx 8.5$ with sulfuric acid or sodium hydroxide, as requested. Potassium chromate solution $(5 \%, 1 \mathrm{~mL})$ was then added and the mixture titrated against $\mathrm{AgNO}_{3}(0.05 \mathrm{~mol} / \mathrm{L})$ until the first reddish colour (precipitate) appears. The salt concentration was then calculated using the equation: Salt content $\%=[(\mathrm{V}$ titrated of $\left.\left.\mathrm{AgNO}_{3} \times 0.00292\right)\right] /[(\mathrm{m}$ sample $)] \times 100$ and expressed as $\mathrm{g} / 100 \mathrm{~g}$ dry weight $(\mathrm{dw})$.

Free sugars composition. Free sugars were identified and quantified using high performance liquid chromatography with refractive index detection (HPLC-RI) (Fernandes et al., 2016). The equipment integrates a pump (Knauer, Smartline system 1000, Berlin, Germany), a degasser system (Smartline manager 5000), an autosampler (AS-2057 Jasco) and an RI detector (Knauer Smartline 2300) and a column oven operating at $30^{\circ} \mathrm{C}$ (7971 R Grace oven). The chromatographic separation was achieved with a Eurospher 100-5 NH2 column $(5 \mu \mathrm{m}, 4.6 \mathrm{~mm} \times 250 \mathrm{~mm}$, Knauer). Quantification was conducted by the internal standard method (IS, raffinose), and using calibration curves obtained from commercial standards. The results were recorded and processed using Clarity 2.4 software (DataApex, Prague, Czech Republic). Sugar contents were expressed in $\mathrm{g}$ per $100 \mathrm{~g}$ of $\mathrm{dw}$.

Fatty acids composition. Samples ( $1.5 \mathrm{~g})$ were extracted using a Soxhlet apparatus with petroleum ether as solvent. The samples undergo transesterification according to the procedure previously reported by Fernandes et al. (2016). Analysis was carried out using gas chromatography (DANI 1000, Contone, Switzerland), equipped with a split/splitless injector and a flame ionization detector (FID at $260{ }^{\circ} \mathrm{C}$ ). Separation was achieved with a Macherey-Nagel (Duren, Germany) column (50\% cyanopropyl-methyl- $50 \%$ phenylmethylpolysiloxane, $30 \mathrm{~m} \times 0.32 \mathrm{~mm}$ ID $\times 0.25 \mu \mathrm{m} \mathrm{df}$ ). Fatty acids identification was made by comparison with relative retention times of FAME peaks of standard samples. The results were recorded and processed using CSW 1.7 software (DataApex 1.7, Prague, Czech Republic), and expressed in relative percentage (\%).

Tocopherols composition. Tocopherols were determined by HPLC with fluorescence detection (FP-2020; Jasco, Easton, MD, USA) using excitation at $290 \mathrm{~nm}$ and emission at $330 \mathrm{~nm}$ (Fernandes et al., 2016). The chromatographic separation was achieved with a Polyamide II $(5 \mu \mathrm{m}, 250 \mathrm{~mm} \times 4.6 \mathrm{~mm})$ normal-phase column from YMC Waters (Dinslaken, Germany) operating at $30^{\circ} \mathrm{C}$. Quantification was based on calibration curves obtained from commercial standards using the IS (tocol) methodology. The results were expressed in $\mu \mathrm{g}$ per $100 \mathrm{~g}$ of $\mathrm{dw}$.

Total polysaccharides. Total polysaccharides were determined according to Vazirian et al. (2014) with some modifications. Briefly, 
dry sample ( $1.5 \mathrm{~g}$ ) was extracted by maceration with boiling water and further filtered under vacuum; this step was repeated twice. The filtrated extract was lyophilized and the polysaccharide fraction dissolved in water at a concentration of $5 \mathrm{mg} / \mathrm{mL}$. This solution $(1 \mathrm{~mL})$ was mixed with phenol $(4 \%, 25 \mu \mathrm{L})$ followed by sulphuric acid $(1 \mathrm{~mL})$. The sample solutions were then stirred for $30 \mathrm{~s}$ and their absorbance measured at $548 \mathrm{~nm}$ against a blank (distilled water), using a UV-visible-light spectrophotometer (UV-160A; Shimadzu Corporation, Kyoto, Japan). Starch $(5-50 \mu \mathrm{g} / \mathrm{mL})$ was used as a standard and the results were expressed as mg of starch equivalents per $\mathrm{g}$ of $\mathrm{dw}$.

Total terpenoids. Total terpenoids were determined according to the procedure described by Ghorai et al. (2012). Dry sample $(800 \mathrm{mg})$ was extracted with methanol $(10 \mathrm{~mL})$ for $1 \mathrm{~h}$ and subsequently filtered. Afterwards, the supernatant $(1 \mathrm{~mL})$ was mixed with chloroform $(0.4 \mathrm{~mL})$ and sulphuric acid $(0.6 \mathrm{~mL})$. The sample absorbance was measured at $538 \mathrm{~nm}$ against a blank (methanol added with the other reagents), using a UV-visible-light spectrophotometer (UV-160A; Shimadzu Corporation, Kyoto, Japan). Linalool $(0.1875-6 \mathrm{mg} / \mathrm{mL}$ in methanol) was used as a standard and results were expressed in $\mathrm{mg}$ of linalool equivalents per $\mathrm{g}$ of $\mathrm{dw}$.

Total triterpenes. The triterpenes' content was evaluated according to the protocol described by Chang et al. (2012). Shortly, G. lucidum extract $(10 \mathrm{mg})$ was dissolved in methanol $(1 \mathrm{~mL})$, afterwards an aliquot $(100 \mu \mathrm{L})$ of this solution was mixed with vanillin-glacial acetic acid solution $(150 \mu \mathrm{L}, 5 \% \mathrm{w} / \mathrm{v})$ and perchloric acid solution ( $500 \mu \mathrm{L}, 70 \%)$. Then the sample solutions were heated at $60{ }^{\circ} \mathrm{C}$ for $45 \mathrm{~min}$ and let to cool in an ice-water bath followed by the addition of glacial acetic acid $(2.25 \mathrm{~mL})$. Subsequently, absorbance was measured at $548 \mathrm{~nm}$ against a blank (methanol with other reagents), using a UV-visible-light spectrophotometer (UV160A; Shimadzu Corporation, Kyoto, Japan). Ursolic acid $(0.0078-0.5 \mathrm{mg} / \mathrm{mL}$ in methanol) was used as standard. Results were expressed as mg ursolic acid equivalents per $\mathrm{g}$ of $\mathrm{dw}$.

\subsection{G. lucidum ethanolic extracts and characterization}

Extraction procedure. The dried powder of G. lucidum ( $3 \mathrm{~g}$ ) was extracted in a Soxhlet apparatus for $5-6 \mathrm{~h}$ (35 \pm 5 min per cycle) using ethanol. Finally, the solvent was evaporated under reduced pressure (rotary evaporator Büchi R-210, Flawil, Switzerland) to obtain the dried ethanolic extracts.

Individual triterpenes and phenolic compounds composition. For the individual phenolic and triterpenoid compounds characterization, the obtained extracts were dissolved in ethanol $(5.5 \mathrm{mg} / \mathrm{mL})$, filtered through a $0.22 \mu \mathrm{m}$ nylon syringe filter and analyzed by HPLC-DAD-ESI/MSn in a Dionex Ultimate 3000 UPLC system (ThermoScientific, San Jose, CA, USA). The equipment consisted of a diode array detector coupled to an electrospray ionization mass detector, a quaternary pump, an auto-sampler (kept at $5{ }^{\circ} \mathrm{C}$ ), a degasser and an automated thermostated column section (kept at $\left.35{ }^{\circ} \mathrm{C}\right)$. Waters Spherisorb S3 ODS-2 $\mathrm{C}_{18}(3 \mu \mathrm{m}, 4.6 \times 150 \mathrm{~mm}$, Waters, Milford, MA, USA) column was used. The solvents used were (A) $0.1 \%$ formic acid in water and (B) acetonitrile. The gradient elution applied was: $15 \%$ B (0-5 $\mathrm{min}), 15 \%$ B to $20 \%$ B (5-10 min), $20-25 \%$ B (10-20 $\mathrm{min}), 25-35 \%$ B (20-30 $\mathrm{min}), 35-50 \%$ B (30-40 min), the column was then re-equilibrated, using a flow rate of $0.5 \mathrm{~mL} / \mathrm{min}$. Data was collected simultaneously with DAD $(280 \mathrm{~nm})$ and in negative mode detection on a Linear Ion Trap LTQ XL mass spectrometer (ThermoScientific, San Jose, CA, USA), following a procedure previously described by Bessada et al. (2016). Xcalibur $^{\mathbb{B}}$ data system (ThermoScientific, San Jose, CA, USA) was used in data acquisition. For identification, retention times, UV-VIS and mass spectra were compared with available standards; when not available data from literature was used to tentatively identify the remaining compounds. Quantification was based on calibration curves of available phenolic and triterpenoid standards constructed based on the UV signal. Compounds with unavailable commercial standards were quantified using the calibration curve of the most similar available standard. The results were expressed as $\mathrm{mg} / \mathrm{g}$ of extract.

Antioxidant activity. The antioxidant activity was evaluated by DPPH radical-scavenging activity and reducing power (Taofiq et al., 2016b). The extract concentrations providing 50\% of antioxidant activity or 0.5 of absorbance $\left(\mathrm{EC}_{50}\right)$ were calculated from the graphs of antioxidant activity percentages for DPPH or absorbance at $690 \mathrm{~nm}$ for reducing power assay, against extract concentrations. Trolox was used as positive control.

Antityrosinase activity: Tyrosinase inhibition assay was performed using L-DOPA as substrate according to the procedure described by Taofiq et al. (2016b). The ethanolic extract was dissolved in $50 \%$ DMSO at $10 \mathrm{mg} / \mathrm{mL}$. Assays were carried out in a 96well microplate with each well containing $40 \mu \mathrm{L}$ of the sample, $80 \mu \mathrm{L}$ of phosphate buffer $(0.1 \mathrm{M}, \mathrm{pH} 6.8), 40 \mu \mathrm{L}$ of tyrosinase enzyme (60 units $/ \mathrm{mL}$ ) and $40 \mu \mathrm{L}$ of L-DOPA (3.5 mM). The percentage of tyrosinase inhibition was calculated as follows: [(Acontrol - Asample)/Acontrol] $\times 100$. EC $_{50}$ values were calculated from the calibration curve of tyrosinase inhibition percentage versus extract concentration.

Anti-inflammatory activity. The LPS-induced NO production by Murine macrophage (RAW 264.7) cell lines was determined as nitrite concentration in the culture medium according to the method previously described by Taofiq et al. (2016b). Dexamethasone $(50 \mu \mathrm{M})$ was used as a positive control. The mouse macrophage-like cell line RAW 264.7 stimulated with LPS was used in the assay. Nitric oxide (NO) production was studied with Griess Reagent System kit. Results were expressed as $\mathrm{EC}_{50}$ values $(\mu \mathrm{g} / \mathrm{mL})$ equal to the sample concentration providing a $50 \%$ inhibition of NO production. Dexamethasone was used as positive control.

Cytotoxicity in human tumour cell lines. The cytotoxicity was determined using four human tumour cell lines, HeLa (cervical carcinoma), HepG2 (hepatocellular carcinoma), MCF-7 (breast adenocarcinoma) and NCI-H460 (non-small cell lung cancer), following a procedure already descried by the authors Souza et al. (2015). The cell growth inhibition was measured using the sulforhodamine B assay, were the number of pigmented cells is directly proportional to the total protein mass and therefore to the number of bounded cells. The results were expressed in $\mathrm{GI}_{50}$ values; sample concentration that inhibited $50 \%$ of the net cell growth and ellipticine was used as positive control.

Cytotoxicity in non-tumour liver cells primary culture. A freshly harvested porcine liver, obtained from a local slaughter house, was used in order to obtain the cell culture, designated as PLP2. The growth inhibition was evaluated using the SRB assay, as previously described by Abreu et al. (2011). The results were expressed in $\mathrm{GI}_{50}$ values; sample concentration that inhibited $50 \%$ of the net cell growth and ellipticine was used as positive control.

Antimicrobial activity. The tested bacterial strains were clinical isolates obtained from patients hospitalized in various departments at the Hospital Center of Trás-os-Montes and Alto Douro (Vila Real, Portugal). Four Gram-positive bacteria (Enterococcus faecalis, isolated from urine; Listeria monocytogenes, methicillin-resistant Staphylococcus aureus (MRSA), isolated from expectoration; methicillin-sensitive $S$. aureus (MSSA), isolated from wound exudate), six Gram-negative bacteria (Escherichia coli, E. coli ESBL, Klebsiella pneumoniae, K. Pneumoniae ESBL; Morganella morganii, and Proteus mirabilis, all isolated from urine; Pseudomonas aeruginosa, isolated from expectoration). The yeast, Candida albicans (isolated from urine) was also tested. Microorganism's identification and susceptibility tests were performed by the microdilution 
method according to Taofiq et al. (2016b).

The microorganisms were cultivated and the determination of the minimal inhibitory concentration (MIC) was performed on a 96-well microplate by the method $p$-iodonitrotetrazolium chloride (INT) colorimetric assay antimicrobial activity was evaluated according to (Taofiq et al., 2016b). The ethanolic extract was dissolved in $25 \%$ DMSO at $50 \mathrm{mg} / \mathrm{mL}$. Initially, $100 \mu \mathrm{L}$ of the extract solution was added to $380 \mu \mathrm{L}$ of culture medium; afterwards, $20 \mu \mathrm{L}$ of inoculum $\left(1.5 \times 10^{8} \mathrm{CFU} / \mathrm{mL}\right)$ was added thus achieving a concentration range of 10 to $0.156 \mathrm{mg} / \mathrm{mL}$. The plates were then incubated at $37^{\circ} \mathrm{C}$, for $24 \mathrm{~h}$, in an oven (Jouan, Berlin, Germany) and the MIC concentrations were determined after adding INT $(0.2 \mathrm{mg} / \mathrm{mL})$ and after incubation at $37{ }^{\circ} \mathrm{C}$ for $30 \mathrm{~min}$. Viable microorganisms reduced the yellow dye to a pink color. MIC was defined as the lowest extract concentration that prevented this change, thus showing complete inhibition of bacterial growth.

\subsection{Development of cosmeceutical formulations based on G. lucidum ethanolic extracts}

Incorporation of the extracts in a base cream. A cosmetic cream with a light colour, free of fragrances, colorants, parabens, mineral oils, sodium lauryl sulphate (SLS), propylene glycol, and ethoxylates purchased from Fagron Iberica S.A.U. (Barcelona, Spain) was used. According to the technical data available, this formulation has been certified to be safe by the US Food and Drug Administration (FDA), Regulation (EC) No 1907/2006-REACH and the National Health Surveillance Agency (ANVISA) of Brazil. The incorporation was achieved according to Taofiq et al. (2016b).

In order to cover all the bioactive properties evaluated, the base creams were incorporated with 5 times the $\mathrm{EC}_{50}$ and MIC values obtained for the extract which corresponds to a scale of $50 \mathrm{mg}$ of extract per gram of base cream. The formulation was continuously mixed until sample homogenisation is fully achieved. The samples were stored at $4{ }^{\circ} \mathrm{C}$ till chemical characterization, evaluation of bioactivity and determination of physicochemical properties.

Colour and $\mathrm{pH}$ measurements. The colour and $\mathrm{pH}$ measurements were performed according to Caleja et al. (2017). The colour of each cosmeceutical formulation was measured using a colorimeter (model CR-400, Konica Minolta Sensing Inc., Tokyo, Japan). Measurements were sampled in three different points, and the average considered the true colour value. Colour space values were registered using the data software "Spectra Magic Nx" (version CMS100W 2.03.0006). The $\mathrm{pH}$ measurement was performed, in triplicate, directly in the cream with a HI 99161 pH-meter (Hanna Instruments, Woonsocket, Rhode Island, USA).

Bioactive properties. The cosmeceutical formulations were dissolved in an aqueous solution of $50 \%$ DMSO at $50 \mathrm{mg} / \mathrm{mL}$ for antioxidant activity evaluation; in $50 \%$ DMSO at $50 \mathrm{mg} / \mathrm{mL}$ for antityrosinase activity and in 5\% DMSO at $100 \mathrm{mg} / \mathrm{mL}$ for antimicrobial activity evaluation (following the procedures described previously). The cosmeceutical formulations were extracted with methanol $(20 \mathrm{~mL})$ for $30 \mathrm{~min}$, filtered, dried in a rotary evaporator, and re-dissolved in ethanol:water $(20: 80 \mathrm{v} / \mathrm{v})$ for phenolic acids and triterpenes' analysis.

\section{Results and discussion}

\subsection{Nutritional and chemical properties of G. lucidum fruiting bodies}

The results for the nutritional composition of Ganoderma lucidum are presented in Table 1. Carbohydrates were the most abundant compounds, followed by proteins, fat, ash and salt. The results are fairly consistent with the ones reported by Stojković et al. (2014)
Table 1

Nutritional and chemical composition of G. lucidum fruiting bodies.

\begin{tabular}{ll}
\hline Component & Mean $\pm \mathrm{SD}$ \\
\hline Nutritional value (g/100 g) & \\
\hline Lipids & $2.50 \pm 0.02$ \\
Proteins & $6.72 \pm 0.04$ \\
Ash & $2.4 \pm 0.2$ \\
Available carbohydrates & $38.0 \pm 0.7$ \\
Total carbohydrates & $88.4 \pm 0.2$ \\
Energy (kcal/100 g) & $201 \pm 3$ \\
NaCl & $0.42 \pm 0.02$ \\
\hline Free sugars (g/100 g) & \\
\hline Fructose & $2.15 \pm 0.04$ \\
\hline Tocopherols ( $\mathbf{g} / \mathbf{1 0 0}$ g) & \\
\hline alpha-Tocopherol & $18.1 \pm 0.2$ \\
delta-Tocopherol & $123 \pm 7$ \\
\hline Fatty acids (\%) & \\
\hline C16:0 & $21.3 \pm 0.3$ \\
C18:0 & $5.8 \pm 0.2$ \\
C18:1n9 $18: 2 n 6$ & $12.7 \pm 0.1$ \\
SFA (\%) & $42.4 \pm 0.1$ \\
MUFA (\%) & $39.3 \pm 0.4$ \\
PUFA (\%) & $14.3 \pm 0.1$ \\
\hline Total content of biomolecules & $46.4 \pm 0.3$ \\
\hline Polysaccharides (mg starch/g) & $27.2 \pm 0.7$ \\
Terpenoids (mg linalool/g) & $5.6 \pm 0.5$ \\
\hline Triterpenoids (mg ursolic acid/g) & \\
\hline & \\
\hline
\end{tabular}

Values are expressed in dry weight basis. ${ }^{*} 17$ more fatty acids were identified (data not shown) but with relative percentages lower than $3 \%$. SFA- Saturated Fatty Acids; MUFA- Monounsaturated Fatty Acids; PUFA- Polyunsaturated Fatty Acids. Palmitic acid (C16:0); stearic acid (C18:0); oleic acid (C18:1n-9); linoleic acid (C18:2n6).

even though the origin of the samples was different (Serbia). Regarding the free sugars, fructose was the only one identified in G. lucidum. Regarding the fatty acids (Table 1), polyunsaturated fatty acids (PUFA) were the most abundant ones due to the high contribution of linoleic acid followed by saturated fatty acids (SFA) and monounsaturated fatty acids (MUFA). These results suggest $G$. lucidum as an important dietary source of PUFAs, which have been reported as effective agents in the support of the general body wellbeing by preventing several chronic diseases (Wang et al., 2012). Concerning the tocopherols, the alpha and delta isoforms were found in $G$. lucidum, being $\delta$-tocopherol the most abundant one (Table 1 ). This molecule has received special attention due to its reported health promoting benefits and potent antioxidant properties, being highly used in clinical dermatology, as photoprotection skin agents against UV radiation (Thiele and EkanayakeMudiyanselage, 2007). A very common trend in the pharmaceutical and cosmetic industries involve the use of nutritional supplements to manage health conditions; including a popular term used among dermatologist and cosmetic formulators is "beauty pills", which involve the use of compounds such as vitamins, lycopene, retinol, essential fatty acids and other compounds with antioxidant properties to improve skin appearance (Draelos, 2010).

G. lucidum is therefore considered a complete "package" of healthy food, being an excellent source of nutritional components, as well as, of other non-nutritional compounds. When orally ingested it is able to improve body function and wellbeing. Total polysaccharides, terpenoids and triterpenoids were determined (Table 1 ), being terpenoids the most abundant ones, followed by polysaccharides and triterpenoids. The polysaccharide content is partially in accordance with the one reported for strains of $G$. lucidum sourced in Poland (about $18.45 \mathrm{mg}$ glucose equiv/g dw) 
and analysed by Skalicka-Woźniak et al. (2012). The triterpene content reported in the present work was consistent with the one recently described by Liu et al. (2017), where the triterpene amount of $\mathrm{G}$. lucidum was about $5.90 \mathrm{mg}$ ursolic acid equiv/g dw.

Commercially, there are already available some nutraceutical products containing G. lucidum extract, either alone or in combination with other mushroom species. Some of them include Organic Rare Red Reishiт (100\% G. lucidum); Organic ReiShi-Gen (50\% G. lucidum and 50\% Lentinula edodes); Organic TrimycoGen $^{\mathrm{TM}}$ (33\% Cordyceps sinensis 33\% G. lucidum 33\% L. Edodes). These products formulated in capsules, rich in triterpenes and $\beta$-glucans, have been recently reported by Rathore et al. (2017) to protect the body against oxidative stress and support the immune system. In conclusion, formulating nutraceuticals from $\mathrm{G}$. lucidum have shown to present interesting health promoting benefits.

\subsection{G. lucidum ethanolic extracts as relevant bioactive extracts}

The ethanolic extracts of G. lucidum were analysed by HPLCDAD-ESI/MS and the obtained profiles included phenolic acids and triterpenic acids. Data regarding retention time, maximum wavelengths, molecular ion and main fragment ions observed in $\mathrm{MS}^{2}$, compounds identification and individual quantification are presented in Table 2. A total of three phenolic acids (peaks 1-3), identified by comparing their UV spectra, retention time and MS fragmentation pattern with the ones of commercial standards, were found in the G. lucidum extract, with $p$-hydroxybenzoic acid being the most abundant. Concerning published data, protocatechuic and $p$-hydroxybenzoic acids are the most widely reported phenolic acids in G. lucidum. Nevertheless, Yildiz et al. (2015) have also detected the presence of syringic acid in the methanolic extracts from this matrix, which is consistent with results achieved in this work. Heleno et al. (2012) and Stojković et al. (2014) also reported the presence of $p$-coumaric and cinnamic acids in the fruiting body of G. lucidum, but differences in the extraction procedure, and used environment for mushroom maturation can justify the dissimilarity found in the achieved phenolic composition and other secondary metabolites profiles.

A total of 26 triterpenoids (peaks 4-7, 9-27 and 29-31) were identified (Table 2), being four of them identified as ganoderic acid derivatives and other two as unknown compounds (peaks 8 and 28 ). Thus, these unknown compounds could possibly be related with triterpenoid acids presence. In fact, an ESI-MS spectrum in negative mode was used in the present study and all triterpenoids gave $[\mathrm{M}-\mathrm{H}]^{-}$and $[2 \mathrm{M}-\mathrm{H}]^{-}$ions in their negative ion mass spectra. The triterpenoids identified in the present work resulted from a comparison with literature data, regarding the UV spectra, retention time and MS fragmentation pattern, namely with the one reported for triterpenoids in the works of Guo et al. (2012); Liu et al. (2014); Pecić et al. (2015); Qi et al. (2012) \&Yang et al. (2007), which also studied $G$. lucidum samples. Ganoderic acid $\mathrm{H}$, followed by ganoderic acid $\mathrm{C} 2$ and ganoderic acid $\mathrm{A}$ were the most abundant triterpenoids acids present. Yang et al. (2007) and Hadda et al. (2015) reported the presence of ganoderenic acid $\mathrm{K}$ in chloroform extracts of G. lucidum from China and Algeria, suggesting that the triterpenoids profile depends on the extraction method employed (namely used solvent) and the geographical origin of the strain. However, most studies have reported a good repeatability in the triterpenoids profile of G. lucidum (Hadda et al., 2015; Hennicke et al., 2016; Yang et al., 2007).

The results regarding the bioactivity of G. lucidum extracts are presented in Table 3. The antioxidant results obtained are very similar to the ones reported by Heleno et al. (2012) for DPPH radical scavenging and reducing power, even though the authors performed a different extraction procedure (maceration in methanol:water mixture $(80: 20, v / v))$. These authors also conducted studies concerning phenolic and polysaccharidic extracts of G. lucidum, being the antioxidant activity slightly lower in the latter, suggesting that phenolic compounds play a more prominent role in the free radical scavenging activity.

G. lucidum ethanolic extract also revealed tyrosinase inhibition activity. To the authors best knowledge only Chien et al. (2008) have reported the tyrosinase inhibition activity for ethanolic extract of $G$. lucidum from Taiwan with a reported $\mathrm{EC}_{50}$ reaching $0.32 \mathrm{mg} / \mathrm{mL}$, lower than the one obtained herein, possibly justified by the used slightly different procedures. Kim et al. (2016) were able to identify a bioactive compound, ganodermanondiol, which suppressed the expression of tyrosinase-related protein (TRP-1, TRP-2) and microphthalmia-associated transcription factor (MITF) thereby inhibiting the synthesis of melanin. Tyrosinase inhibitors have shown to be effective ingredients towards skin lightening, and among the bioactive compounds found in mushrooms, phenolics have been reported as the ones that contribute most significantly to their antityrosinase activity (Taofiq et al., 2016a). Therefore, the ethanolic extract studied in the present work can be further exploited as a tyrosinase inhibitor to reduce the severity of hyperpigmentation and decrease melanin biosynthesis, partly due to the registered amount on phenolic acids. Regarding the antiinflammatory activity, aqueous, methanolic and ethanolic extracts of G. lucidum presented activity mainly by inhibiting NO, PGE2, TNF- $\alpha$ IL1- $\beta$ production (Taofiq et al., 2016c). In the present study, ethanolic extract of $G$. lucidum revealed anti-inflammatory activity by inhibiting NO production. Even though the phenolic compounds of mushrooms have been identified as the most important contributors to their anti-inflammatory activity (Taofiq et al., 2015), triterpenic acids such as ganoderic acid $\mathrm{C} 1$ and lanostane in $G$. lucidum, have also contributed significantly to its antiinflammatory activity (Taofiq et al., 2016c).

The numerous secondary metabolites contained in this mushroom have attracted huge interest and one of the most complete reported studies is the one on its cytotoxic effect (Amen et al., 2016; Li et al., 2013b). In the present work, no toxicity was observed in non-tumour porcine liver cells (PLP2) at the maximum tested concentration $(400 \mu \mathrm{g} / \mathrm{mL})$. However, the extract was able to inhibit all human tumour cell lines evaluated; with breast carcinoma cells showing to be the most susceptible cells, followed by non-small cell lung, hepatocellular and cervical carcinoma cells. Our results against cervical carcinoma cells were mostly in line with the ones reported by Ćilerdžić et al. (2014) with a growth inhibitory effect of $61.17 \pm 0.75 \mu \mathrm{g} / \mathrm{mL}$, even though mushroom origin (Serbia) and applied extraction procedure (maceration) were different. The results also correlated well with the statements reported by Reis et al. (2015) for methanolic extract, namely a similar trend on the registered activity was observed (MCF-7 > NCI-H460). Overall, a lot of studies have been able to identify the titerpenes as the most prominent class of compounds contributing to the shown cytotoxic effect (Amen et al., 2016; Chen et al., 2016; Li et al., 2013a). The mechanism of antitumour effect of this mushroom has been associated with inducing autophagy (Reis et al., 2015), leading to apoptosis, inhibition of tumour invasion and metastasis (Patel and Goyal, 2012).

Finally, among the analysed bacterial strains, G. lucidum extract showed the highest antibacterial activity against MSSA and MRSA with corresponding lowest minimum inhibitory concentrations (Table 3). Regarding the Gram-positive bacteria strains, Listeria monocytogenes was the least inhibited followed by Enteroccocus faecalis. For Gram negative bacteria, the extract was not able to inhibit the growth of Morganella morganii and Pseudomonas aeruginosa even at the highest tested concentration, while the two $E$. coli and the two Klebsiella strains were inhibited. In brief, the 
Table 2

Identification and quantification of triterpenes and phenolic acids in G. lucidum ethanolic extract.

\begin{tabular}{|c|c|c|c|c|c|c|}
\hline Peak & $\begin{array}{l}\mathrm{Rt} \\
(\mathrm{min})\end{array}$ & $\begin{array}{l}\text { UV } \lambda_{\max } \\
(\mathrm{nm})\end{array}$ & $\begin{array}{l}{[\mathrm{M}-\mathrm{H}]^{-} \text {and }} \\
{[2 \mathrm{M}-\mathrm{H}]^{-}} \\
(\mathrm{m} / \mathrm{z})\end{array}$ & $\begin{array}{l}\mathrm{MS}^{2} \text { and } \mathrm{MS}^{3} \\
(\mathrm{~m} / \mathrm{z})\end{array}$ & Tentative identification & $\begin{array}{l}\text { Quantification } \\
(\mathrm{mg} / \mathrm{g})\end{array}$ \\
\hline \multicolumn{7}{|c|}{ Phenolic acids } \\
\hline 1 & 5.23 & $259,293 \mathrm{sh}$ & 153 & 109(100) & Protocatequic acid & $1.807 \pm 0.001$ \\
\hline 2 & 8.39 & 257 & 137 & $93(100)$ & $p$-Hydroxybenzoic acid & $2.98 \pm 0.01$ \\
\hline \multirow[t]{2}{*}{3} & 11.51 & 280 & 197 & $121(100)$ & Syringic acid & $1.51 \pm 0.01$ \\
\hline & & & & & Total phenolic acid & $6.30 \pm 0.01$ \\
\hline \multicolumn{7}{|c|}{ Triterpenes } \\
\hline 4 & 29.06 & 259 & $533 / 1067$ & $515(5), 497(12), 404(100), 303(12)$ & $\begin{array}{l}\text { 3,7,15-Trihydroxy-4- } \\
\text { (hydroxymethyl)-11,23-dioxo-lanost-8-en-26-oic acid }\end{array}$ & $14.21 \pm 0.02$ \\
\hline 5 & 30.8 & 256 & $533 / 1067$ & $515(5), 497(21), 453(16), 423(11), 319(5), 303(8)$ & 12-Hydroxyganoderic acid C2 & $4.51 \pm 0.06$ \\
\hline 6 & 31.27 & 252 & $529 / 1059$ & $511(10), 467(100), 449(11), 434(5), 431(15), 419(8), 312(8), 285(5), 263(11)$ & 20-hydroxy-ganoderic acid AM1 & $11.40 \pm 0.01$ \\
\hline 7 & 31.73 & 251 & $529 / 1059$ & $511(13), 499(100), 481(6), 465(18), 438(28), 419(18), 367(11), 287(11)$ & 12-deacetylganoderic acid $\mathrm{H}$ & $6.1 \pm 0.1$ \\
\hline 8 & 32.28 & 255 & $547 / 1095$ & $529(50), 511(41), 485(3), 467(100), 449(24), 431(26), 304(11), 265(7)$ & Ganoderic acid derivative & $7.3 \pm 0.13$ \\
\hline 9 & 33.94 & 258 & $531 / 1063$ & $513(13), 451(3), 401(100), 385(5), 304(19), 301(45), 286(3), 249(27)$ & Ganoderic acid $\eta$ & $25.41 \pm 0.04$ \\
\hline 10 & 34.48 & 254 & $511 / 1023$ & 493(23),449(100),431(5),413(15),405(3) & Ganoderic acid $\mathrm{F}$ & $17.97 \pm 0.02$ \\
\hline 11 & 35.37 & 265 & $529 / 1059$ & $511(5), 467(100), 449(20), 437(29), 317(10), 301(5), 263(5)$ & 12-hydroxyganoderic acid D & $6.86 \pm 0.07$ \\
\hline 12 & 35.95 & 251 & $515 / 1031$ & $497(100), 453(31), 437(8), 303(19), 287(5), 235(3)$ & Ganoderic acid derivative & $21.20 \pm 0.08$ \\
\hline 13 & 36.84 & 256 & $517 / 1035$ & $499(100) 481(48), 456(17), 438(52), 407(8), 304(6), 287(35)$ & Ganoderic acid C2 & $38.7 \pm 0.2$ \\
\hline 14 & 37.51 & 257 & $529 / 1059$ & $511(5), 481(7), 467(100), 451(14), 438(38), 424(3), 319(5), 303(3), 301(5)$ & Ganoderic acid C6 & $29.10 \pm 0.08$ \\
\hline 15 & 38.16 & 256 & $529 / 1059$ & $511(58), 493(5), 449(10), 399(100), 301(3)$ & Ganoderic acid derivative & $12.77 \pm 0.01$ \\
\hline 16 & 38.46 & 256 & $531 / 1063$ & $513(11), 498(15), 469(100), 454(29), 452(24), 437(6), 304(5), 302(6), 290(20), 266(7)$ & Ganoderic acid G & $16.84 \pm 0.07$ \\
\hline 17 & 38.75 & 248 & $513 / 1027$ & $495(10), 480(16), 451(100), 437(14), 433(22), 407(17), 331(5), 315(3), 303(5), 287(5)$ & Ganoderenic acid B & $10.66 \pm 0.09$ \\
\hline 18 & 39.01 & 259 & $527 / 1055$ & $509(26), 465(6), 397(100), 355(4)$ & Elfvingic acid derivative & $10.41 \pm 0.09$ \\
\hline 19 & 39.35 & 254 & $515 / 1031$ & $497(10), 453(100), 439(5), 409(5), 304(21), 287(12), 263(3), 250(14)$ & Ganoderic acid B & $23.99 \pm 0.09$ \\
\hline 20 & 39.46 & 250 & $513 / 1027$ & $495(100), 479(27), 462(12), 451(30), 433(31), 381(25), 301(15)$ & Ganoderic acid derivative & $22.4 \pm 0.1$ \\
\hline 21 & 39.66 & 261 & $513 / 1027$ & $495(21), 480(5), 451(100), 433(24), 381(6), 301(6), 247(3)$ & Ganoderic acid AM1 & $15.82 \pm 0.01$ \\
\hline 22 & 40.29 & 254 & $515 / 1031$ & $497(100), 480(5), 454(6), 436(10), 302(8), 301(4), 285(3)$ & Ganoderic acid A & $36.77 \pm 0.04$ \\
\hline 23 & 40.66 & 261 & $571 / 1143$ & $553(100), 511(8), 481(3), 468(8), 437(3), 423(2)$ & Ganoderic acid $\mathrm{H}$ & $41.1 \pm 0.4$ \\
\hline 24 & 40.87 & 252 & $527 / 1055$ & $509(20), 479(13), 465(100), 435(3), 421(3), 317(3), 301(3)$ & Elfvingic acid $\mathrm{A}$ & $9.83 \pm 0.01$ \\
\hline 25 & 41.34 & 254 & $529 / 1059$ & $511(10), 496(22), 493(21), 467(100), 449(61), 434(4), 319(6), 317(8), 301(16), 300(11), 299(12)$ & Ganoderic acid derivative & $11.56 \pm 0.04$ \\
\hline 26 & 41.93 & 246 & $511 / 1023$ & $493(12), 478(20), 449(100), 435(15), 431(4), 405(4), 329(3), 301(4), 285(5), 283(3), 261(4)$ & Ganoderenic acid D & $10.27 \pm 0.07$ \\
\hline 27 & 42.55 & 255 & $513 / 1027$ & $495(16), 451(100), 437(6), 433(3), 407(4), 301(23), 286(3), 284(11), 247(8)$ & Ganoderic acid D & $11.31 \pm 0.01$ \\
\hline 28 & 42.74 & 245 & $509 / 1019$ & $491(100), 476(18), 461(34), 447(15), 429(3), 417(3), 300(5), 299(4)$ & Ganoderic acid derivative & $12.81 \pm 0.08$ \\
\hline 29 & 43.15 & 256 & $511 / 1023$ & $493(100), 449(65), 435(3), 300(5), 247(4)$ & Ganoderic acid E & $10.81 \pm 0.07$ \\
\hline 30 & 43.95 & 255 & $569 / 1139$ & $551(100), 509(35), 508(21), 466(8)$ & 12-acetoxyganoderic acid $\mathrm{F}$ & $12.08 \pm 0.07$ \\
\hline \multirow[t]{2}{*}{31} & 44.92 & 272 & $513 / 1027$ & $451(100), 437(8), 433(3), 422(3), 301(5)$ & Ganoderic acid J & $2.92 \pm 0.05$ \\
\hline & & & & & Total triterpenoids & $455 \pm 1$ \\
\hline
\end{tabular}

Calibration curves used: 1-protocatechuic acid ( $\left.\mathrm{y}=214168 \mathrm{x}+27102 ; R^{2}=0.999\right) ; 2$ - $p$-hydroxybenzoic acid ( $\left.\mathrm{y}=208604 \mathrm{x}+173056 ; R^{2}=0.999\right) ; 3$ - syringic acid $\left(\mathrm{y}=376056 \mathrm{x}+141329 ; R^{2}=0.999\right) ; 4$ - ganoderic acid $\mathrm{A}$ $\left(\mathrm{y}=2539.7 \mathrm{x}+16193 ; R^{2}=0.999\right)$. 
Table 3

Bioactive properties of $G$. lucidum ethanolic extract.

\begin{tabular}{|c|c|}
\hline & $\begin{array}{l}\text { G.lucidum } \\
\text { ethanolic extract }\end{array}$ \\
\hline \multicolumn{2}{|l|}{ Antioxidant activity $\left(\mathrm{EC}_{50}\right.$ values, $\mathrm{mg} / \mathrm{mL}$ ) } \\
\hline DPPH scavenging activity & $0.73 \pm 0.01$ \\
\hline Reducing power & $0.15 \pm 0.01$ \\
\hline \multicolumn{2}{|l|}{ Cytotoxic activity $\left(\mathrm{GI}_{50}\right.$ values, $\mu \mathrm{g} / \mathrm{mL}$ ) } \\
\hline MCF-7 (breast carcinoma) & $61 \pm 4$ \\
\hline $\mathrm{NCI}-\mathrm{H} 460$ (non-small cell lung carcinoma) & $64 \pm 3$ \\
\hline HeLa (cervical carcinoma) & $73 \pm 3$ \\
\hline HepG2 (hepatocellular carcinoma) & $68.44 \pm 0.08$ \\
\hline PLP2 (non-tumour primary liver porcine cells) & $>400$ \\
\hline \multicolumn{2}{|l|}{ Anti-inflammatory activity $\left(\mathrm{EC}_{50}, \mu \mathrm{g} / \mathrm{mL}\right)$} \\
\hline NO Inhibition & $112 \pm 1$ \\
\hline \multicolumn{2}{|l|}{ Antityrosinase activity $\left(\mathrm{EC}_{50}\right.$ values, $\mathrm{mg} / \mathrm{mL}$ ) } \\
\hline L-DOPA assay & $2.81 \pm 0.01$ \\
\hline \multicolumn{2}{|l|}{ Antimicrobial activity (MIC, mg/mL) } \\
\hline \multicolumn{2}{|l|}{ Gram positive } \\
\hline Enterococcus faecalis & 10 \\
\hline Listeria monocytogenes & 20 \\
\hline MSSA & 5 \\
\hline MRSA & 5 \\
\hline \multicolumn{2}{|l|}{ Gram negative } \\
\hline Eschericia coli & 10 \\
\hline Eschericia coli ESBL & 10 \\
\hline Klebsiella pneumoniae & 20 \\
\hline Klebsiella pneumoniae ESBL & 20 \\
\hline Morganella morganii & $>20$ \\
\hline Pseudomonas aeruginosa & $>20$ \\
\hline Proteus mirabilis & 20 \\
\hline Candida albicans & $>20$ \\
\hline
\end{tabular}

The antioxidant activity was expressed as $\mathrm{EC}_{50}$ values, where lower values correspond to higher antioxidant potential. Trolox (positive control) $\mathrm{EC}_{50}$ values: $41 \mu \mathrm{g} /$ $\mathrm{mL}$ (reducing power), $42 \mu \mathrm{g} / \mathrm{mL}$ (DPPH scavenging activity). Anti-inflammatory activity is expressed as $\mathrm{EC}_{50}$ values corresponding to $50 \%$ of inhibition of the NO production in comparison with the negative control (100\% of NO production). Dexamethasone (positive control) $\mathrm{EC}_{50}$ values: $16 \mu \mathrm{g} / \mathrm{mL}$. Anti-tyrosinase activity is expressed as $\mathrm{EC}_{50}$ values corresponding to $50 \%$ of inhibition of tyrosinase. Ascorbic acid (positive control) $\mathrm{EC}_{50}$ values: $31 \mu \mathrm{g} / \mathrm{mL}$. Cytotoxicity results are expressed as $\mathrm{GI}_{50}$ values corresponding to the sample concentration responsible for $50 \%$ of growth inhibition in human tumour cell lines or in liver primary culture PLP2. Ellipticine (positive control) $\mathrm{GI}_{50}$ values: $1.21 \mu \mathrm{g} / \mathrm{mL}$ (MCF-7), $1.03 \mu \mathrm{g} / \mathrm{mL}$ (NCI$\mathrm{H} 460$ ), $0.91 \mu \mathrm{g} / \mathrm{mL}$ (HeLa), $1.10 \mu \mathrm{g} / \mathrm{mL}$ (HepG2) and 2.29 (PLP2). Minimum Inhibitory concentration-MIC, MRSA- Methicillin-resistant Staphylococcus aureus; MSSA methicillin susceptible $S$. aureus; ESBL-spectrum extended producer of $\beta$ lactamase.

extract was able to inhibit both Gram negative and Gram-positive bacteria. The antimicrobial activity of G. lucidum has been widely studied, and according to the review conducted by Alves et al. (2013), extracts of $G$. lucidum revealed antimicrobial activity against $B$. subtilis, $S$. aureus, E. coli, K. pneumoniae, P. aeruginosa, $S$. typhi, and S. Typhimurium. The phenolic acids present in this mushroom have been identified as the most important contributors to this activity (Heleno et al., 2013). These authors went further to evaluate the antimicrobial activity of these phenolic acids derivatives (glucuronated and methylated) to confirm if they reveal activity in their in vivo form after undergoing metabolism. In the review conducted by Ferreira et al. (2015) the polysaccharide fractions have also been described to contribute significantly to the antimicrobial activity of this mushroom. Thus, further studies need to be conducted with this extract by testing other bacterial and fungal strains to confirm its broad spectrum of antimicrobial activity.

\subsection{G. lucidum ethanolic extracts in cosmeceutical formulations}

The term "cosmeceutical" was first introduced by Albert
Kligman, MD, Ph.D in 1984 at the National Scientific Meeting of the Society of Cosmetic Chemists (Kligman, 2006). This term is an interphase between cosmetics and pharmaceuticals since they are products formulated with bioactive ingredients, topically applied on the skin to produce a medical drug-like benefit, while also improving skin structure and function (Taofiq et al., 2016a). The use of bioactive products such as vitamins, peptides, phenolic compounds, polyhydroxy acids, obtained from plant, mushroom and other natural matrices, as cosmeceutical ingredients, have received increased attention because of their multifunctional benefits on skin (e.g. antioxidant, antityrosinase, anti-hyaluronidase, anticollagenase, anti-elastase, photoprotective, antimicrobial and antiinflammatory).

In the present study, the results of antioxidant, antimicrobial and antityrosinase activities for the produced cosmeceutical formulation are presented in Table 4 . The cosmeceutical formulations maintain the bioactivities exhibited by the extract. This achievement is quite interesting regarding the concern of cosmetic industry in reducing the presence of synthetic ingredients, and its gradual replacement by natural counterparts, due to the increased awareness on the negative effects reported for some artificial antimicrobial agents. In fact, natural bioactive compounds with a broad spectrum of antimicrobial properties are being slowly introduced in this industrial field, also justified by their multifunctional properties (Kerdudo et al., 2016). The formulations incorporated with G. lucidum extract were able to significantly inhibit the growth of MSSA and MRSA by presenting a low minimum inhibitory concentration. Also, this work demonstrates that extracts of G. lucidum have interesting biological properties that can be exploited in the design of cosmeceutical formulations either as tyrosinase inhibitors, anti-inflammatory agents or as preservatives to prolong the shelf life of the formulated product. The compounds earlier identified in the ethanolic extract were monitored by HPLCDAD-ESI/MS and found to be present in the produced cosmeceutical formulation.

The relevance of G. lucidum properties is evident from the

Table 4

Physico-chemical and bioactive properties of G. lucidum cosmeceutical formulation.

\begin{tabular}{ll}
\hline & G. lucidum cosmeceutical formulation \\
\hline Physico-chemical properties & \\
\hline Colour & \\
$L^{*}$ & $70.3 \pm 0.7$ \\
$a^{*}$ & $12.1 \pm 0.5$ \\
$b^{*}$ & $32.9 \pm 0.9$ \\
$\mathrm{pH}$ & $4.61 \pm 0.03$
\end{tabular}

Bioactive properties

Antioxidant activity $\left(\mathrm{EC}_{50}\right.$ values, $\mathrm{mg} / \mathrm{mL}$ )

DPPH scavenging activity $\quad 34 \pm 1$

$\begin{array}{ll}\text { Reducing power } & 13.60 \pm 0.09\end{array}$

Antityrosinase activity $\left(\mathrm{EC}_{50}\right.$ values, $\left.\mu \mathrm{g} / \mathrm{mL}\right)$

$\begin{array}{ll}\text { L-DOPA assay } & 23.80 \pm 0.03\end{array}$

Antimicrobial activity (MIC, mg/mL)

Enterococcus faecalis 200

Listeria monocy

MSSA

MRSA

400

400
100

100

Eschericia coli

Eschericia coli ESBL

Klebsiella pneumoniae

Klebsiella pneumoniae ESBL

Morganella morganii

Pseudomonas aeruginosa

Proteus mirabilis

Candida albicans
200

200

400

400

$>400$

$>400$

400

$>400$ 
number of commercial cosmeceutical products in the market formulated from their extracts, either alone or in combination with other natural ingredients. Examples include Body Repair Lotion (G. lucidum extract and medicinal plant), Dr. Andrew Weil for Origins ${ }^{\mathrm{TM}}$ Mega-Mushroom Skin Relief Face Mask (G. lucidum, C. sinensis and medicinal plants) and Menard Embellir Refresh Massage cream ( $G$. lucidum and $G$. sinense). These products have all been used to suppress the severity of hyperpigmentation, to brighten skin appearance and prevent aging effects, and to protect skin against UV radiation (Taofiq et al., 2016a). Even though the individual contribution of their constituents needs to be established, there are reports claiming that terpenes such as monoterpenes and sesquiterpenes have potential to enhance compound penetration across the skin by decreasing skin barrier resistance of the stratum corneum (Lane, 2013). Thus, the content of terpenoids determined for G. lucidum can play an important role by enhancing the topical availability of other constituents in cosmeceutical formulations.

In today's cosmetic market a wide variety of choices is offered to consumers, being colour attributes an important characteristic for their acceptance. Hence, companies have paid lots of attention in managing colour display during product design and formulation. In the present work, the colour attributes of the produced cosmeceutical formulation showed a light-yellow colouration. The rate of dermal absorption of topical formulations such as lotions and creams are often influenced by the $\mathrm{pH}$ of the product. The $\mathrm{pH}$ of skin external surface is around 5.5, and at this condition, the skin micro-flora, barrier homeostasis and stratum corneum are maintained (Ali and Yosipovitch, 2013; Martínez-Pla et al., 2004). Most reports have suggested that a pH between 4 and 6.5 can be considered as adequate for cosmetic formulations since most pathogenic bacteria (e.g. S. aureus), thrive best at neutral $\mathrm{pH}$ levels (Ali and Yosipovitch, 2013). In the present work, the cosmeceutical formulation presented a $\mathrm{pH} 4.6$, which is considered within the favourable $\mathrm{pH}$ range.

\section{Conclusion}

Overall, beyond the important nutritional composition of $G$. lucidum that can be essential for nutraceutical's development, its ethanolic extract showed several bioactive properties ideal to be exploited in the development of cosmeceutical formulations. The presence of different bioactive molecules in the classes of phenolic compounds, terpenes, specially triterpenes can be correlated with the exhibited bioactivity. Even so, further studies needed to be conducted in order to better understand the mechanism of action of G. lucidum metabolites and identify the most important subtypes behind each observed bioactivity. Furthermore, issues related with stability, skin permeation, efficacy and topical bioavailability are major concerns that need to be addressed. Hence, conducting skin permeation studies using in vitro skin models, the use of nanotechnology techniques as bioactive compound delivery system and evaluating the stability of the formulations prepared at different storage time and temperature will further confirm the potential of G. lucidum extracts as topical ingredients. Also, further in vivo and clinical studies are necessary in order to develop and validate novel nutraceuticals, cosmeceuticals and pharmacological formulations.

\section{Acknowledgement}

The authors are grateful to the Foundation for Science and Technology and FEDER for CIMO (UID/AGR/00690/2013) and to POCI-01-0145-FEDER-006984 (LA LSRE-LCM) funded by ERDF through POCI-COMPETE2020 and FCT. To NORTE-01-0145-FEDER000006, funded by NORTE 2020, under PT2020 through FERDF. Also for financial support to S.A.H. (SFRH/BPD/101413/2014) grant and L.B and R.M.C. contracts. A.M.G.-P. is also thankful to the Spanish MINECO/FEDER for financial support through the project AGL2015-64522-C2-2-R.

\section{Conflicts of interest}

No conflict of interest.

\section{Transparency document}

Transparency document related to this article can be found online at http://dx.doi.org/10.1016/j.fct.2017.07.051.

\section{References}

Abreu, R.M.V., Ferreira, I.C.F.R., Calhelha, R.C., Lima, R.T., Vasconcelos, M.H., Adega, F. Chaves, R., Queiroz, M.J.R.P., 2011. Anti-hepatocellular carcinoma activity using human HepG2 cells and hepatotoxicity of 6-substituted methyl 3-aminothieno [3,2-b]pyridine-2- carboxylate derivatives: in vitro evaluation, cell cycle analysis and QSAR studies. Eur. J. Med. Chem. 46, 5800-5806. http://dx.doi.org/ 10.1016/j.ejmech.2011.09.029.

Ali, S.M., Yosipovitch, G., 2013. Skin pH: from basic science to basic skin care. Acta Derm. Venereol. 93, 261-267. http://dx.doi.org/10.2340/00015555-1531.

Alves, M.J., Ferreira, I.C.F.R., Dias, J., Teixeira, V., Martins, A., Pintado, M., 2013 A review on antimicrobial activity of mushroom extracts and isolated compounds. Planta Med. 78, 1707-1718. http://dx.doi.org/10.1055/s-0032-1315370.

Amen, Y.M., Zhu, Q., Afifi, M.S., Halim, A.F., Ashour, A., Shimizu, K., 2016. New cytotoxic lanostanoid triterpenes from Ganoderma lingzhi. Phytochem. Lett. 17, 64-70. http://dx.doi.org/10.1016/j.phytol.2016.07.024.

AOAC International, 2016. Official Methods of Analysis of AOAC International, vol 44.

Baby, S., Johnson, A.J., Govindan, B., 2015. Secondary metabolites from ganoderma.

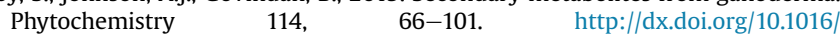
j.phytochem.2015.03.010.

Bessada, S.M.F, Barreira, J.C.M., Barros, L, Ferreira, I.C.F.R, Oliveira, M.B.P.P, 2016 Phenolic profile and antioxidant activity of Coleostephus myconis (L.) Rchb.f.: an underexploited and highly disseminated species. Ind. Crops Prod. 89, 45-51. http://dx.doi.org/10.1016/j.indcrop.2016.04.065.

Bishop, K.S., Kao, C.H.J., Xu, Y., Glucina, M.P., Paterson, R.R.M., Ferguson, L.R., 2015 From 2000 years of Ganoderma lucidum to recent developments in nutraceuticals. Phytochemistry 114, 56-65. http://dx.doi.org/10.1016 j.phytochem.2015.02.015.

Caleja, C., Barros, L., Antonio, A.L., Oliveira, M.B.P.P., Ferreira, I.C.F.R., 2017 A comparative study between natural and synthetic antioxidants: evaluation of their performance after incorporation into biscuits. Food Chem. 216, 342-346. http://dx.doi.org/10.1016/j.foodchem.2016.08.075.

Chang, C.L., Lin, C.S., Lai, G.H., 2012. Phytochemical characteristics, free radical scavenging activities, and neuroprotection of five medicinal plant extracts. Evidence-based Complement. Altern. Med. http://dx.doi.org/10.1155/2012/ 984295, 2012.

Chen, S.Y., Chang, C.L., Chen, T.H., Chang, Y.W., Bin, Lin.S, 2016. Colossolactone H, a new Ganoderma triterpenoid exhibits cytotoxicity and potentiates drug efficacy of gefitinib in lung cancer. Fitoterapia 114, 81-91. http://dx.doi.org/10.1016/ j.fitote.2016.08.015.

Chien, C.C., Tsai, M.L., Chen, C.C., Chang, S.J., Tseng, C.H., 2008. Effects on tyrosinase activity by the extracts of Ganoderma lucidum and related mushrooms. Mycopathologia 166, 117-120. http://dx.doi.org/10.1007/s11046-008-9128-x.

Ćilerdžić, J., Vukojević, J., Stajić, M., Stanojković, T., Glamočlija, J., 2014. Biological activity of Ganoderma lucidum basidiocarps cultivated on alternative and commercial substrate. J. Ethnopharmacol. 155, 312-319. http://dx.doi.org 10.1016/j.jep.2014.05.036.

Draelos, Z.D., 2010. Nutrition and enhancing youthful-appearing skin. Clin. Dermatol 28, 400-408. http://dx.doi.org/10.1016/j.clindermatol.2010.03.019.

Fernandes, Â., Barreira, J.C.M., Antonio, A.L., Oliveira, M.B.P.P., Martins, A Ferreira, I.C.F.R., 2016. Extended use of gamma irradiation in wild mushrooms conservation: validation of $2 \mathrm{kGy}$ dose to preserve their chemical characteristics. LWT - Food Sci. Technol. 67, 99-105. http://dx.doi.org/10.1016 j.lwt.2015.11.038.

Ferreira, I.C.F.R., Heleno, S.A., Reis, F.S., Stojkovic, D., Queiroz, M.J.R.P. Vasconcelos, M.H., Sokovic, M., 2015. Chemical features of Ganoderma polysaccharides with antioxidant, antitumor and antimicrobial activities. Phytochemistry 114, 38-55. http://dx.doi.org/10.1016/j.phytochem.2014.10.011.

Ghorai, N., Chakraborty, S., Shamik, G., Saha, S.K., Biswas, S., 2012. Estimation of total Terpenoids concentration in plant tissues using a monoterpene, Linalool as standard reagent. Protoc. Exch. 1-6. http://dx.doi.org/10.1038/protex.2012.055.

Grienke, U., Kaserer, T., Pfluger, F., Mair, C.E., Langer, T., Schuster, D., Rollinger, J.M., 2015. Accessing biological actions of Ganoderma secondary metabolites by in silico profiling. Phytochemistry 114, 114-124. http://dx.doi.org/10.1016 j.phytochem.2014.10.010.

Guo, X.-Y., Han, J., Ye, M., Ma, X.-C., Shen, X., Xue, B.-B., Che, Q.-M., 2012 
Identification of major compounds in rat bile after oral administration of total triterpenoids of Ganoderma lucidum by high-performance liquid chromatography with electrospray ionization tandem mass spectrometry. J. Pharm. Biomed. Anal. 63, 29-39. http://dx.doi.org/10.1016/j.jpba.2012.01.030.

Hadda, M., Djamel, C., Akila, O., 2015. Production and qualitative analysis of triterpenoids and steroids of ganoderma species harvested from cork oak forest of North-Eastern Algeria. Res. J. Microbiol. 10, 366-376. http://dx.doi.org/10.3923/ jm.2015.366.376.

Heleno, S.A., Barros, L., Martins, A., Queiroz, M.J.R.P., Santos-Buelga, C., Ferreira, I.C.F.R., 2012. Fruiting body, spores and in vitro produced mycelium of Ganoderma lucidum from Northeast Portugal: a comparative study of the antioxidant potential of phenolic and polysaccharidic extracts. Food Res. Int. 46 135-140. http://dx.doi.org/10.1016/j.foodres.2011.12.009.

Heleno, S.A., Ferreira, I.C.F.R., Esteves, A.P., Ćirić, A., Glamočlija, J., Martins, A., Soković, M., Queiroz, M.J.R.P., 2013. Antimicrobial and demelanizing activity of Ganoderma lucidum extract, p-hydroxybenzoic and cinnamic acids and their synthetic acetylated glucuronide methyl esters. Food Chem. Toxicol. 58, 95-100. http://dx.doi.org/10.1016/j.fct.2013.04.025.

Hennicke, F., Cheikh-Ali, Z., Liebisch, T., Maclá-Vicente, J.G., Bode, H.B. Piepenbring, M., 2016. Distinguishing commercially grown Ganoderma lucidum from Ganoderma lingzhi from Europe and East Asia on the basis of morphology, molecular phylogeny, and triterpenic acid profiles. Phytochemistry $127,29-37$. http://dx.doi.org/10.1016/j.phytochem.2016.03.012.

Kerdudo, A., Burger, P., Merck, F., Dingas, A., Rolland, Y., Michel, T., Fernandez, X., 2016. Development of a natural ingredient - natural preservative: a case study Comptes Rendus Chim. 19, 1077-1089. http://dx.doi.org/10.1016/ j.crci.2016.06.004.

Kim, J.-W., Kim, H.-I., Kim, J.-H., Kwon, O.-C., Son, E.-S., Lee, C.-S., Park, Y.-J., 2016 Effects of ganodermanondiol, a new melanogenesis inhibitor from the medicinal mushroom ganoderma lucidum. Int. J. Mol. Sci. 17, 1798. http://dx.doi.org 10.3390/ijms17111798.

Kligman, A., 2006. The future of cosmeceuticals: an interview with Albert Kligman, MD, PhD. Dermatol. Surg. 31, 890-891. http://dx.doi.org/10.1111/j.15244725.2005 .31737$.

Lane, M.E., 2013. Skin penetration enhancers. Int. J. Pharm. 447, 12-21. http:// dx.doi.org/10.1016/j.ijpharm.2013.02.040.

Li, P., Deng, Y.-P., Wei, X.-X., Xu, J.-H., 2013a. Triterpenoids from Ganoderma lucidum and their cytotoxic activities. Nat. Prod. Res. 27, 17-22. http://dx.doi.org/ 10.1080/14786419.2011.652961.

Li, Y.B., Liu, R.M., Zhong, J.J., 2013b. A new ganoderic acid from Ganoderma lucidum mycelia and its stability. Fitoterapia 84, 115-122. http://dx.doi.org/10.1016 j.fitote.2012.11.008.

Liu, L.-Y., Chen, H., Liu, C., Wang, H.-Q., Kang, J., Li, Y., Chen, R.-Y., 2014. Triterpenoids of Ganoderma theaecolum and their hepatoprotective activities. Fitoterapia 98 254-259. http://dx.doi.org/10.1016/j.fitote.2014.08.004.

Liu, S.-R., Ke, B.-R., Zhang, W.-R., Liu, X.-R., Wu, X.-P., 2017. Breeding of new Ganoderma lucidum strains simultaneously rich in polysaccharides and triterpenes by mating basidiospore-derived monokaryons of two commercial cultivars. Sci. Hortic. Amst. 216, 58-65. http://dx.doi.org/10.1016/ j.scienta.2016.12.016.

Liu, Y., Zhang, J., Tang, Q., Yang, Y., Xia, Y., Zhou, S., Wu, D., Zhang, Z., Dong, L, Cui, S.W., 2016. Rheological properties of $\beta$-D-glucan from the fruiting bodies of Ganoderma lucidum. Food Hydrocoll. 58, 120-125. http://dx.doi.org/10.1016/ j.foodhyd.2016.01.025.

Liu, Z., Xing, J., Huang, Y., Bo, R., Zheng, S., Luo, L., Niu, Y., Zhang, Y., Hu, Y., Liu, J., Wu, Y., Wang, D., 2016a. Activation effect of Ganoderma lucidum polysaccharides liposomes on murine peritoneal macrophages. Int. J. Biol. Macromol. 82, 973-978. http://dx.doi.org/10.1016/j.ijbiomac.2015.10.088.

Liu, Z., Xing, J., Zheng, S., Bo, R., Luo, L., Huang, Y., Niu, Y., Li, Z., Wang, D., Hu, Y., Liu, J., Wu, Y., 2016b. Ganoderma lucidum polysaccharides encapsulated in liposome as an adjuvant to promote Th1-bias immune response. Carbohydr. Polym. 142, 141-148. http://dx.doi.org/10.1016/j.carbpol.2016.01.021.

Martínez-Pla, J.J., Martín-Biosca, Y., Sagrado, S., Villanueva-Camañas, R.M., MedinaHernández, M.J., 2004. Evaluation of the $\mathrm{pH}$ effect of formulations on the skin permeability of drugs by biopartitioning micellar chromatography. J. Chromatogr. A 1047, 255-262. http://dx.doi.org/10.1016/j.chroma.2004.07.011.

Min-Young, K., Philippe, S., Joung-Kuk, Jong-Jin, K., Se-Chul, C., Eun-Hye, K., SuHyun, S., Eun-Young, K., Sun-Lim, K., Yool-Jin, P., Hee-Myong, R., 2008. Phenolic compound concentration and antioxidant activities of edible and medicina mushrooms from Korea. J. Agric. Food Chem. 56, 7265-7270.

Osaili, T.M., Al-Nabulsi, A.A., Olaimat, A.N., Shaker, R.R., Taha, M., Holley, R.A., 2014 Survival of Escherichia coli 0157:H7 during manufacture and storage of white brined cheese. J. Food Sci. 79, M1750-M1755. http://dx.doi.org/10.1111/17503841.12547.

Patel, S., Goyal, A., 2012. Recent developments in mushrooms as anti-cancer therapeutics: a review. 3 Biotech. 2, 1-15. http://dx.doi.org/10.1007/s13205-0110036-2.

Pecić, S., Nikićević, N., Veljović, M., Jardanin, M., Tešević, V., Belović, M., Nikšić, M.,
2015. The influence of extraction parameters on physicochemical properties of special grain brandies with Ganoderma lucidum. Chem. Ind. Chem. Eng. Q. 22, 1-22. http://dx.doi.org/10.2298/CICEQ150426033P.

Qi, Y., Zhao, L., Sun, H.H., 2012. Development of a rapid and confirmatory method to identify ganoderic acids in Ganoderma mushrooms. Front. Pharmacol. 3 MAY, 1-7. http://dx.doi.org/10.3389/fphar.2012.00085.

Rathore, H., Prasad, S., Sharma, S., 2017. Mushroom nutraceuticals for improved nutrition and better human health: a review. PharmaNutrition 5, 35-46. http:// dx.doi.org/10.1016/j.phanu.2017.02.001.

Reis, F.S., Lima, R.T., Morales, P., Ferreira, I.C.F.R., Vasconcelos, M.H., 2015. Methanolic extract of ganoderma lucidum induces autophagy of AGS human gastric tumor cells. Molecules 20, 17872-17882. http://dx.doi.org/10.3390/ molecules201017872.

Sheikh, I.A., Vyas, D., Ganaie, M.A., Dehariya, K., Singh, V., 2014. HPLC determination of phenolics and free radical scavenging activity of ethanolic extracts of two polypore mushrooms. Int. J. pf Pharm. Pharm. Sci. 6, 679-684.

Skalicka-Woźniak, K., Szypowski, J., Łoś, R., Siwulski, M., Sobieralski, K., Głowniak, K., Malm, A., 2012. Evaluation of polysaccharides content in fruit bodies and their antimicrobial activity of four Ganoderma lucidum (W Curt.: Fr.) P. Karst. strains cultivated on different wood type substrates. Acta Soc. Bot. Pol. 81, 17-21. http://dx.doi.org/10.5586/asbp.2012.001.

Souza, A.H.P., Corrêa, R.C.G., Barros, L., Calhelha, R.C., Santos-Buelga, C., Peralta, R.M., Bracht, A., Matsushita, M., Ferreira, I.C.F.R., 2015. Phytochemicals and bioactive properties of Ilex paraguariensis: an in-vitro comparative study between the whole plant, leaves and stems. Food Res. Int. 78, 286-294. http://dx.doi.org/ 10.1016/j.foodres.2015.09.032.

Stojković, D.S., Barros, L., Calhelha, R.C., Glamočlija, J., Ćirić, A., van Griensven, L.J.L.D., Soković, M., Ferreira, I.C.F.R., 2014. A detailed comparative study between chemical and bioactive properties of Ganoderma lucidum from different origins. Int. J. Food Sci. Nutr. 65, 42-47. http://dx.doi.org/10.3109/ 09637486.2013 .832173$.

Taofiq, O., Calhelha, R.C., Heleno, S., Barros, L., Martins, A., Santos-Buelga, C., Queiroz, M.J.R.P., Ferreira, I.C.F.R., 2015. The contribution of phenolic acids to the anti-inflammatory activity of mushrooms: screening in phenolic extracts, individual parent molecules and synthesized glucuronated and methylated derivatives. Food Res. Int. 76, 821-827. http://dx.doi.org/10.1016/ j.foodres.2015.07.044.

Taofiq, O., González-Paramás, A.M., Martins, A., Barreiro, M.F., Ferreira, I.C.F.R. 2016a. Mushrooms extracts and compounds in cosmetics, cosmeceuticals and nutricosmetics-A review. Ind. Crops Prod. 90, 38-48. http://dx.doi.org/10.1016/ j.indcrop. 2016.06.012.

Taofiq, O., Heleno, S., Calhelha, R., Alves, M., Barros, L., Barreiro, M., GonzálezParamás, A., Ferreira, I., 2016b. Development of mushroom-based cosmeceutical formulations with anti-inflammatory, anti-tyrosinase, antioxidant, and antibacterial properties. Molecules 21, 1372. http://dx.doi.org/10.3390/ molecules21101372.

Taofiq, O., Martins, A., Barreiro, M.F., Ferreira, I.C.F.R., 2016c. Anti-inflammatory potential of mushroom extracts and isolated metabolites. Trends Food Sci. Technol. 50, 193-210. http://dx.doi.org/10.1016/j.tifs.2016.02.005.

Thiele, J.J., Ekanayake-Mudiyanselage, S., 2007. Vitamin E in human skin: organspecific physiology and considerations for its use in dermatology. Mol. Asp. Med. 28, 646-667. http://dx.doi.org/10.1016/j.mam.2007.06.001.

Van Nguyen, T., Tung, N.T., Cuong, T.D., Hung, T.M., Kim, J.A., Woo, M.H., Choi, J.S., Lee, J.H., Min, B.S., 2015. Cytotoxic and anti-angiogenic effects of lanostane triterpenoids from Ganoderma lucidum. Phytochem. Lett. 12, 69-74. http:// dx.doi.org/10.1016/j.phytol.2015.02.012

Vazirian, M., Dianat, S., Manayi, A., Ziari, R., Mousazadeh, A., Habibi, E., Amanzadeh, Y., 2014. Anti-inflammatory effect, total polysaccharide, total phenolics content and antioxidant activity of the aqueous extract of three basidiomycetes. Res. J. Pharmacogn. 1, 15-21.

Wang, J., Luo, T., Li, S., Zhao, J., 2012. The powerful applications of polyunsaturated fatty acids in improving the therapeutic efficacy of anticancer drugs. Expert Opin. Drug Deliv. 9, 1-7. http://dx.doi.org/10.1517/17425247.2011.618183.

Wu, Y., Choi, M.-H., Li, J., Yang, H., Shin, H.-J., 2016. Mushroom cosmetics: the present and future. Cosmetics 3, 22. http://dx.doi.org/10.3390/ cosmetics3030022.

Yang, M., Wang, X., Guan, S., Xia, J., Sun, J., Guo, H., Guo, D.an, 2007. Analysis of triterpenoids in ganoderma lucidum using liquid chromatography coupled with electrospray ionization mass spectrometry. J. Am. Soc. Mass Spectrom. 18, 927-939. http://dx.doi.org/10.1016/j.jasms.2007.01.012.

Yildiz, O., Can, Z., Laghari, A.Q., Şahin, H., Malkoç, M., 2015. Wild edible mushrooms as a natural source of phenolics and antioxidants. J. Food Biochem. 39, 148-154. http://dx.doi.org/10.1111/jfbc.12107.

Zhao, X.R., Zhang, B.J., Deng, S., Zhang, H.L., Huang, S.S., Huo, X.K., Wang, C., Liu, F., $\mathrm{Ma}, \mathrm{X.C.,}$ 2016. Isolation and identification of oxygenated lanostane-type triterpenoids from the fungus Ganoderma lucidum. Phytochem. Lett. 16, 87-91. http://dx.doi.org/10.1016/j.phytol.2016.03.007. 